\title{
PENGELOLAAN SAMPAH DI TEMPAT PEMBUANGAN AKHIR (TPA) JATIBARANG, KOTA SEMARANG
}

\author{
Intan Muning Harjanti \\ Pratamaningtyas Anggraini ${ }^{2}$ \\ Program Studi Diploma Perencanaan Tata Ruang Wilayah dan Kota, Departemen Sipil dan Perencanaan, \\ Sekolah Vokasi, Universitas Diponegoro, Indonesia ${ }^{12}$ \\ Penulis Korespondensi e-mail : intanmuning@live.undip.ac.id
}

\begin{abstract}
Indonesia's rapid population growth will indirectly affect the increase in waste production. Ineffective and efficient waste management systems will have an impact on the accumulation of waste at the final processing location. Large piles of garbage have the potential to produce gases that are harmful to health and the environment. Jatibarang Final Processing Site is the only final processing location in the city of Semarang, where the final processing location can accommodate sources of waste from 16 sub-districts in the city of Semarang. The purpose of this study is to determine the waste management activities in the Jatibarang final processing site, so that later it can become an input to improve future waste management in the Jatibarang final processing location. The research method used is descriptive qualitative, using primary and secondary data collection techniques.The results of the study explained that the waste management activities at the jatibarang final processing site are, the final scraping of compost, the use of methane gas (CH4) originating from the landfill as an alternative gas (biogas), reducing waste by herding cattle, and the methane canteen program.
\end{abstract}

Keyword: waste, management, Jatibarang

\section{ABSTRAK}

Pertumbuhan penduduk Indonesia yang cepat akan secara tidak langsung mempengaruhi peningkatan produksi limbah. Sistem pengelolaan limbah yang tidak efektif dan efisien akan berdampak pada akumulasi limbah di lokasi pemrosesan akhir. Tumpukan besar sampah berpotensi menghasilkan gas yang berbahaya bagi kesehatan dan lingkungan. Situs Pengolahan Akhir Jatibarang adalah satu-satunya lokasi pemrosesan akhir di kota Semarang, di mana lokasi pemrosesan akhir dapat menampung sumber limbah dari 16 kecamatan di kota Semarang. Tujuan dari penelitian ini adalah untuk mengetahui kegiatan pengelolaan limbah di lokasi pengolahan akhir Jatibarang, sehingga nantinya dapat menjadi input untuk meningkatkan pengelolaan limbah di masa mendatang di lokasi pengolahan akhir Jatibarang. Metode penelitian yang digunakan adalah deskriptif kualitatif, menggunakan teknik pengumpulan data primer dan sekunder. Hasil penelitian menjelaskan bahwa kegiatan pengelolaan limbah di lokasi pemrosesan akhir jatibarang adalah, pengikisan akhir kompos, penggunaan gas metana $(\mathrm{CH} 4)$ yang berasal dari TPA sebagai gas alternatif (biogas), mengurangi limbah dengan menggembalakan ternak, dan program kantin metana.

Kata kunci: limbah, pengelolaan, Jatibarang 
Jurnal Planologi Vol. 17 No. 2, Oktober 2020

Available : http://jurnal.unissula.ac.id/index.php/psa

\section{PENDAHULUAN}

Indonesia sebagai negara tingkat pertumbuhan penduduknya cukup tinggi. Hal ini dapat dilihat pada populasi Indonesia pada tahun 2017 mencapai 261 juta (Tomoutounews, 2017) dan diperkirakan akan terus meningkat hingga mencapai 305.7 juta pada tahun 2035 (UGM, 2017). Pertumbuhan populasi yang dinamis secara tidak langsung akan berdampak pada munculnya berbagai masalah, salah satunya adalah permasalahan sampah. Menurut WHO, sampah merupakan sesuatu yang tidak digunakan, tidak dipakai, tidak disenangi atau sesuatu yang dibuang berasal dari kegiatan manusia dan tidak terjadi dengan sendirinya (Chandra, 2007 dalam Fadhilah et al., 2011) Populasi yang terus meningkat secara signifikan akan meningkatkan jumlah produksi sampah, terutama sampah rumah tangga. Dimana sampah rumah tangga ini adalah sampah yang berasal dari kegiatan sehari-hari di rumah tangga yang tidak termasuk kotoran dan sampah khusus (PP No. 81 Tahun 2012). Tercatat pada 2014 produksi sampah Indonesia mencapai 5,4 juta ton sampah per tahun, yang menjadikan Indonesia penghasil limbah terbesar kedua di dunia (ANTARANews, 2014). Hal ini menunjukkan pentingnya manajemen sampah di suatu kota atau wilayah, karena jika pengelolaan sampah di suatu kota baik, maka akan dapat mewujudkan lingkungan perkotaan yang baik juga. Tetapi sebaliknya jika pengelolaan sampah tidak dilakukan dengan baik, hal itu akan menyebabkan berbagai masalah lingkungan dan kesehatan, seperti pemanasan global.

TPA Jatibarang adalah TPA terbesar di Jawa Tengah yang terletak di Kota Semarang. TPA Jatibarang ini adalah TPA utama yang menampung 70\% dari limbah Kota Semarang, dimana TPA Jatibarang mampu menampung 800 ton sampah per hari. Oleh karena itu, diperlukan suatu penelitian tentang pengelolaan sampah di TPA Jatibarang, sehingga nantinya dapat memberikan arahan untuk memaksimalkan fungsi TPA Jatibarang. Tujuan dari penelitian ini adalah untuk mengidentifikasi kegiatan pengelolaan sampah di TPA Jatibarang Semarang. Sedangkan tahapan yang dilakukan adalah identifikasi lokasi TPA Jatibarang dan analisis pengelolaan sampah di TPA Jatibarang. Metode yang digunakan dalam penelitian ini adalah metode kualitatif deskriptif, dan dalam proses pengumpulan data dilakukan survei primer dan survei sekunder. 


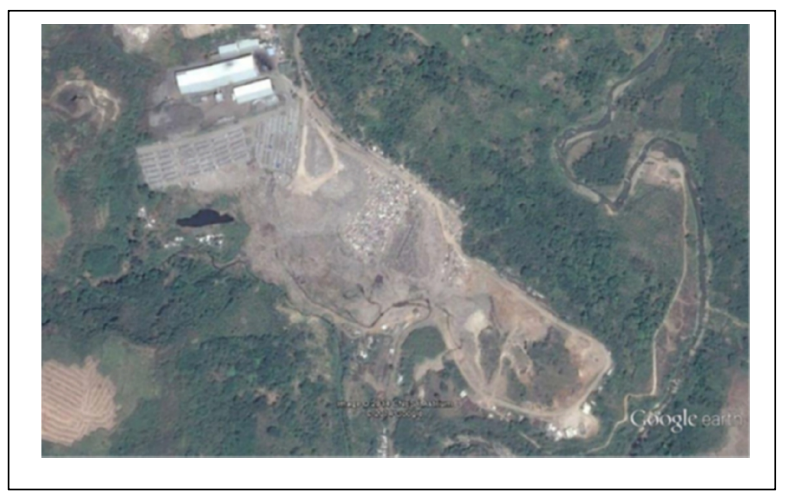

Gambar 1. Foto Udara Wilayah Studi

Sumber : Google Earth, 2017

\section{METODOLOGI}

\subsection{Tempat Pemrosesan Akhir (TPA)}

TPA adalah tempat di mana sampah mencapai tahap akhir dalam pengelolaannya, mulai dari sumber, pengumpulan, pemindahan/ transportasi, pemrosesan hingga pembuangan. Namun di lokasi pemrosesan akhir ini tidak hanya proses pembuangan akhir yang dilakukan, tetapi juga harus ada 4 (kegiatan) utama untuk penanganan sampah di lokasi pembuangan akhir, yaitu (DPU, 2013)

1. Pemilahan sampah

2. Daur ulang limbah non-organik (an-organik)

3. Pengomposan limbah biologis (organik)

4. Akumulasi/ akumulasi limbah residu dari proses di atas di lokasi pengurangan atau penimbunan.

\subsection{Metode}

Metode yang digunakan dalam penelitian ini adalah deskriptif kualitatif, dengan pengumpulan data primer dan sekunder. Pengumpulan data primer dilakukan dengan observasi lapangan, sedangkan pengumpulan data sekunder dengan telaah dokumen. Analisis yang dilakukan adalah Identifikasi kondisi eksisting TPA Jatibarang dan pengelolaan sampah di TPA Jatibarang. Identifikasi kondisi eksisting terdiri dari gambaran keadaan lokasi TPA Jatibarang, sedangkan pengelolaan sampah terdiri dari penjelasan berbagai pengelolaan sampah yang ada di TPA Jatibarang. 
Jurnal Planologi Vol. 17 No. 2, Oktober 2020

Available : http://jurnal.unissula.ac.id/index.php/psa

\section{HASIL DAN PEMBAHASAN}

\subsection{Identifikasi Kondisi Eksisting TPA Jatibarang}

TPA Jatibarang adalah TPA terbesar dan satu-satunya di kota Semarang. Lokasi TPA ini berada di Kelurahan Kedungpane, Kabupaten Mijen, Kota Semarang, dengan total luas $460.183 \mathrm{~m}^{2}$ (46.02 Ha) yang terbagi menjadi:

- Area limbah : 276.469,8 $\mathrm{m}^{2}(27,64 \mathrm{Ha})$

- Infrastruktur : $46.018 \mathrm{~m}^{2}(4.6 \mathrm{Ha})$

- Kolam resapan: $46.018 \mathrm{~m}^{2}(4.6 \mathrm{Ha})$

- Sabuk hijau : $46.018 \mathrm{~m}^{2}(4.6 \mathrm{Ha})$

- Tanah penutup : $46.018 \mathrm{~m}^{2}(4.6 \mathrm{Ha})$

TPA Jatibarang mulai beroperasi pada bulan Maret tahun 1992, yang pengelolaannya dikelola oleh Dinas Sanitasi dan Pertamanan Kota Semarang, tetapi sejak tahun 2016 pengelolaan telah dialihkan ke Badan Lingkungan Hidup Kota Semarang. Pada awalnya, pengelolaan sampah di TPA Jatibarang menggunakan metode pengelolaan sampah dengan dumping terbuka, namun pada tahun 1993-1994 telah beralih menggunakan metode controlled landfill dan pada tahun 1995 beralih ke metode sanitary landfill. Hal ini sejalan dengan UU No 18 Tahun 2008 tentang pengelolaan sampah yang mengharuskan Pemerintah Kabupaten/ Kota untuk menggunakan sanitary landfill system atau paling tidak controlled landfill system sebagai metode pengolahan limbah di TPA. Sanitary landfill, adalah metode penyimpanan sampah ke tanah yang dirancang dan dioperasikan secara sistematis, yang meliputi proses perataan, pemadatan dan penutupan sampah setiap harinya. Sanitary landfill adalah praktik paling umum pembuangan limbah padat kota (municipal solid waste/MSW) di Jerman Barat. Tempat pembuangan sampah ini merupakan sumber polusi potensial untuk permukaan dan air tanah. Untuk mencegah kontaminasi, penyegelan tempat pembuangan akhir. (Ehrig, 1983)

Wahyono (2001), menyebutkan bahwa di negara Amerika Serikat, sanitary landfill menjadi metode penting dalam pengelolaan sampah padat, namun sistem ini akan menjadi sulit dilakukan terutama di kota-kota besar karena lahan yang tersedia sulit dicari. Disisi lain, metode sanitary landfill direkomendasikan untuk menangani sampah di kota-kota besar dan metropolitan dengan menyediakan fasilitas yang sama dengan metode controlled landfill dengan persyaratan (jumlah) dan spesifikasi yang berbeda (ISSDP, 2010). Konsep percobaan controlled landfill dikembangkan sebagai respons terhadap kebutuhan untuk 
Jurnal Planologi Vol. 17 No. 2, Oktober 2020

Available : http://jurnal.unissula.ac.id/index.php/psa

mengoptimalkan pemulihan energi dari tempat pembuangan sampah, mempercepat stabilisasi dan mengendalikan migrasi gas dan bahaya ledakan di sekitar tempat pembuangan sampah. (Haivadakis, Findikakis, Papelis, \& Leckie, 1988) Controlled landfill merupakan salah satu penanganan sampah dengan cara menimbun, yang merupakan peningkatan dari metode open dumping, yaitu dengan mengakumulasi timbunan sampah secara rutin (setiap tujuh hari), melakukan perataan dan pemadatan dalam upaya untuk mengurangi potensi gangguan lingkungan. Dalam penerapan metode controlled landfill, diperlukan fasilitas, seperti:

- Saluran drainase untuk mengontrol air hujan

- Saluran untuk pengumpulan lindi dan instalasi pengolahan

- Pos kontrol operasional

- Fasilitas kontrol gas metana

- Alat berat

Di TPA Jatibarang, sudah tersedia fasilitas drainase untuk mengendalikan air hujan, yaitu berupa sungai. Sedangkan untuk instalasi pengolahan air lindi dan saluran pengumpul lindi juga sudah tersedia, yaitu berupa kolam lindi yang digunakan untuk menyimpan lindi yang dihasilkan sampah sebelum diproses, namun saat ini kolam lindi tersebut sudah tidak digunakan lagi. Fasilitas pos kontrol operasional tersedia di lokasi ini, yang berfungsi sebagai tempat untuk memantau dan mengendalikan kegiatan operasional di lokasi TPA Jatibarang. Fasilitas kontrol gas metana di lokasi ini berbentuk pipa yang diberi pengukur tekanan gas. Hal ini dimaksudkan agar gas metana yang dihasilkan dari proses pengolahan sampah, dapat didistribusikan ke rumah-rumah penduduk sekitar. Alat berat persampahan di lokasi ini sudah tersedia, yang berfungsi untuk memindahkan sampah dan meratakannya. Berdasarkan ketersediaan fasilitas pengolahan sampah di TPA Jatibarang, dapat disimpulkan bahwa di lokasi ini telah dapat menerapkan metode controlled landfill, tetapi penambahan dan pengembangan fasilitas tetap diperlukan, seperti reaktivasi air lindi dan tempat pengolahannya.

\subsection{Pengelolaan Sampah di TPA Jatibarang}

Pada proses pengelolaan limbah, langkah pertama yang harus diperhatikan adalah memilah sampah berdasarkan jenis. Ini akan memudahkan proses pengelolaan limbah selanjutnya. Menurut Damanhuri (2010) klasifikasi jenis limbah di Indonesia didasarkan pada sifat kimia yang dibagi menjadi dua jenis, yaitu:

Intan Muning Harjanti, Pratamaningtyas Anggraini |189

Pengelolaan Sampah di TPA Jatibarang, Kota Semarang 
1. Sampah organik yang terdiri dari bahan-bahan yang membentuk tumbuhan dan hewan yang berasal dari alam.

2. Sampah anorganik yang berasal dari sumber daya alam tidak terbarukan seperti mineral dan minyak bumi, atau dari proses industri.

Pengelolaan sampah didefinisikan sebagai kegiatan yang sistematis, komprehensif dan berkelanjutan yang mencakup pengurangan dan penanganan sampah. Sistem pengelolaan sampah yang komprehensif/ terintegrasi dapat diterapkan mulai dari sumber limbah, pengumpulan, pengangkutan, pemrosesan antara di TPS (Tempat Pembuangan Sementara), dan pemrosesan akhir di TPA (Tempat Pengolahan Akhir) (PP No. 81 Tahun 2012). Proses daur ulang dalam sistem pengolahan sampah terintegrasi dipengaruhi oleh enam aspek, yaitu aspek teknologi, aspek partisipasi masyarakat (sosial), aspek ekonomi dan keuangan, aspek hukum dan peraturan, aspek organisasi dan manajemen, dan aspek operasional (Sucipto, 2012). Sedangkan menurut Undang-Undang No. 18 Tahun 2008 tentang pengelolaan sampah, dijelaskan bahwa yang dimaksud dengan pengelolaan sampah adalah kegiatan yang sistematis, komprehensif dan berkelanjutan yang mencakup pengurangan dan penanganan limbah.

- Pengurangan limbah

Pengurangan sampah adalah upaya untuk mengatasi munculnya sampah dari produsen sampah (rumah tangga, pasar, dll.), menggunakan kembali sampah dari sumbernya dan/ atau di lokasi pengolahan, dan mendaur ulang sampah di sumbernya dan/ atau lokasi pengolahan.

- Penanganan limbah

Serangkaian kegiatan penanganan sampah terdiri dari:

1. Tahap penyaringan/ memilah, adalah pengelompokan dan pemisahan sampah berdasarkan jenis dan sifatnya

2. Tahap pengumpulan adalah, memindahkan sampah dari sumber sampah ke tempat pembuangan sementara (TPS)

3. Tahap pengangkutan, yaitu kegiatan pemindahan sampah dari sumber sampah di tempat pembuangan sementara (TPS) menuju ke tempat pemrosesan akhir (TPA).

4. Pemrosesan akhir sampah di TPA, mengubah bentuk, komposisi, karakteristik dan jumlah sampah, dengan tujuan agar sampah tersebut dapat digunakan kembali atau dapat menyatu ke lahan/ lingkungan

Intan Muning Harjanti, Pratamaningtyas Anggraini $\mid 190$ Pengelolaan Sampah di TPA Jatibarang, Kota Semarang 
Kegiatan daur ulang sampah menjadi salah satu faktor dalam penerapan konsep eko-efisiensi (EE). Konsep EE pertama kali diperkenalkan pada tahun 1992 oleh World Business Council for Sutainable Development (WBCSD) dalam publikasinya Changing Course, yang menyebutkan bahwa terdapat faktor kunci dalam eko-efisiensi, antara lain: mengurangi jumlah penggunaan bahan, mengurangi jumlah penggunaan energi, mengurangi pencemaran, memperbesar daur ulang bahan, memaksimalkan penggunaan SDA yang dapat diperbarui, memperpanjang umur pakai produk, serta meningkatkan intensitas pelayanan (Kementrian Negara LH, 2007 dalam Riswan, Sunoko, \& Hadiyarto, 2012) Proses pengelolaan sampah di lokasi TPA Jatibarang, mulai dari pengumpulan sampah yang berasal dari sumber di beberapa daerah di Semarang, kemudian diangkut menggunakan dumptruck. Setelah itu, sebelum memasuki area pemrosesan akhir, sampah sampah ditimbang berdasarkan jenis (organik dan anorganik) di jembatan timbang yang terletak di bagian depan pintu masuk. Jumlah sampah yang masuk ke lokasi pemrosesan akhir Jatibarang adalah $\pm 800-900$ ton / hari dengan komposisi 62\% sampah organik dan $38 \%$ limbah anorganik (BLH, 2017). Jenis sampah yang mendominasi di lokasi pemrosesan akhir Jatibarang adalah sampah makanan, yaitu 43\%. sedangkan jumlah sampah terkecil adalah jenis tekstil dan popok yang setara dengan $1 \%$.

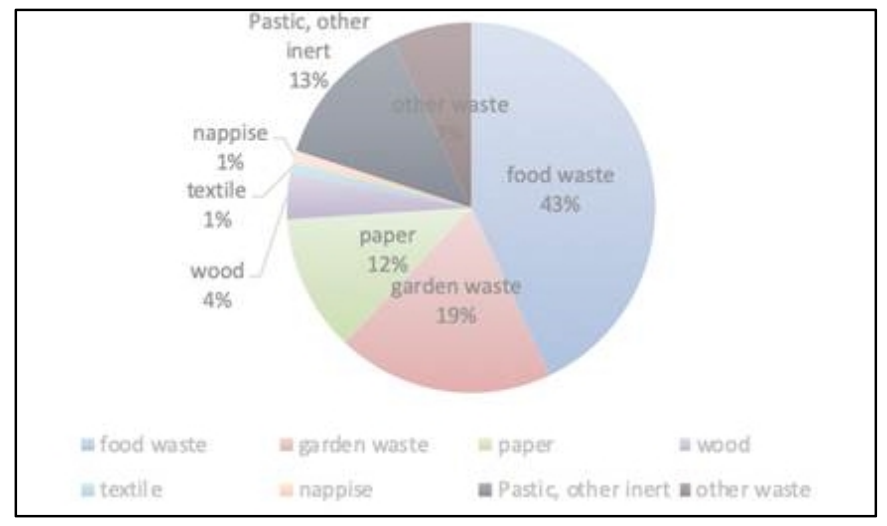

Gambar 2. Komposisi Sampah di TPA Jatibarang Sumber : BLH, 2017

Setelah itu sampah yang telah ditimbang perlahan-lahan ditumpahkan pada lahan pembuangan akhir, yang disesuaikan dengan jenis sampah dan zonanya. Terdapat 4 zona pada lokasi ini, yaitu zona 1 dan 2 merupakan zona aktif yang digunakan untuk pengumpulan sampah dan zona tidak aktif yang digunakan untuk lokasi cadangan pengumpulan sampah, namun jika zona 1 dan 2 tidak dapat menampung sampah, maka sisa sampah yang tidak tertampung akan dikumpulkan pada zona lain yang berisi 
tumpukan sampah tua/ sampah lama. Kegiatan pengelolaan sampah yang terdapat di lokasi TPA Jatibarang, adalah:

\subsubsection{Pengomposan}

Tempat pengomposan tergantung kondisi serta luas lahan (pekarangan rumah) yang dapat disiapkan untuk pembuatan kompos. (Wied, 2004 dalam Sulistyorini, 2005) Proses pengolahan sampah organik dengan pengomposan dilakukan oleh PT. Narpati, yang mengolah limbah organik menjadi pupuk organik, dimana produk akhirnya adalah pupuk granul yang dijual ke Petrokimia Gresik. PT Narpati mampu mengolah 250-350 ton / hari sampah organik menjadi pupuk organik. PT. Narpati adalah perusahaan pengelolaan limbah yang telah berkolaborasi sejak 2010 dan akan berakhir pada 2035 (25 tahun).

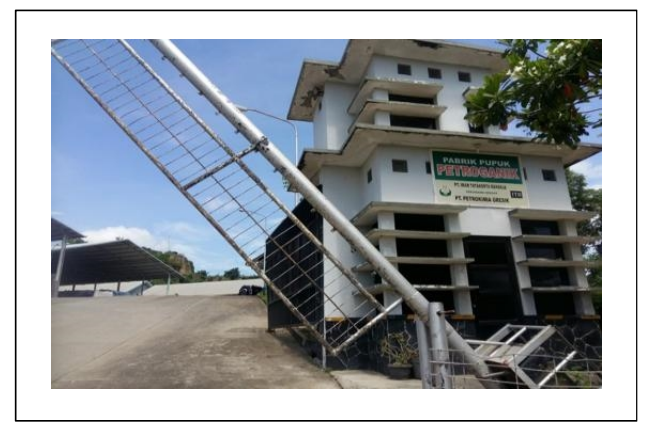

Gambar 3. Rumah Pengomposan di TPA Jatibarang Sumber : Observasi, 2018

\subsubsection{Pemanfaatan Gas Metana (CH4)}

Pemanfaatan gas metana (CH4) sebagai gas alternatif (biogas), dilakukan dengan menancapkan pipa di TPA sedalam kurang lebih 5 meter, kemudian hasil penyerapan gas metana dari limbah/ sampah TPA dialirkan ke rumah-rumah warga sekitar. Gas metana ini dapat digunakan untuk memasak sebagai pengganti cylin gas LPG. Area pemanenan gas di lokasi pemrosesan akhir Jatibarang adalah seluas $\pm 9 \mathrm{Ha}$ (https://bisnis.tempo.co/), dimana dengan menggunakan proses ini dapat mengalirkan gas metana berkapasitas 72 meter kubik dari timbunan sampah di TPA, secara gratis ke 100 rumah warga (https://suaramerdeka.news/). Sistem ini cukup efektif karena selain dapat mengurangi limbah anorganik, juga dapat memberikan manfaat langsung bagi masyarakat untuk kehidupan sehari-hari. 


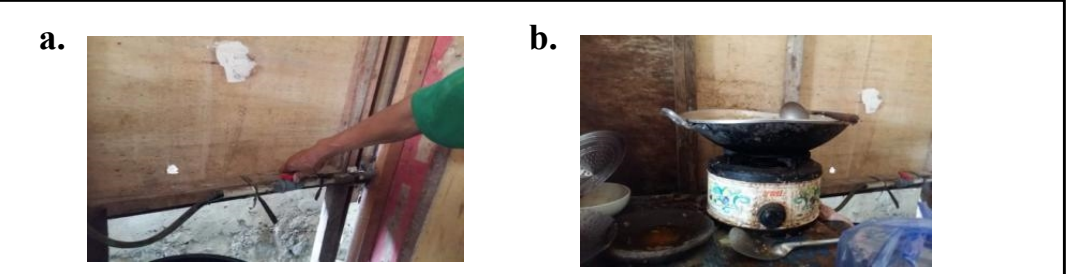

Gambar 4. (a) Pipa Gas Metana; (b) Pemanfaatan Gas Metana untuk Memasak Sumber : Observasi, 2018

\subsubsection{Pengurangan Sampah dengan Kegiatan Penggembalaan Ternak}

Keberadaan kegiatan penggembalaan ternak sapi oleh warga, bertujuan untuk mengurangi volume sampah organik di lokasi TPA Jatibarang. TPA Jatibarang merupakan TPA yang unik dibandingkan TPA lainnya di Indonesia, dimana lahan TPA digunakan sebagai arena untuk penggembalaan ternak oleh warga yang tinggal berdampingan dengan lokasi TPA Jatibarang. Keberadaan sapi-sapi ini telah ada sejak TPA Jatibarang resmi dibuka pada tahun 1992-1993. Awalnya, sapi adalah bantuan dari Pemerintah Kota Semarang sebanyak 120 ekor, sebagai kompensasi yang diterima oleh masyarakat sekitarnya karena pembangunan sebuah pabrik pengolahan makanan di daerah Kedungpane. Karena lahan penggembalaan yang terbatas dan ketidakmampuan untuk menyediakan pakan bagi ternak, sehingga masyarakat sekitar menggembalakan sapi di lokasi TPA Jatibarang ini. Hingga saat ini jumlah sapi masih terus bertambah. Keberadaan pemulung dan sapi dipandang sebagai dilema, pada satu sisi kondisi ini dapat memberikan manfaat karena dapat berkontribusi mengurangi jumlah sampah yang dihasilkan di lokasi TPA, tetapi di sisi lain dapat mengganggu kegiatan operasional di lokasi TPA, terutama mobilitas kendaraan pengangkut sampah. Selain itu, hal terpenting dari kondisi ini adalah bahwa hal tersebut dapat berdampak negatif pada kesehatan para pemulung maupun sapi.

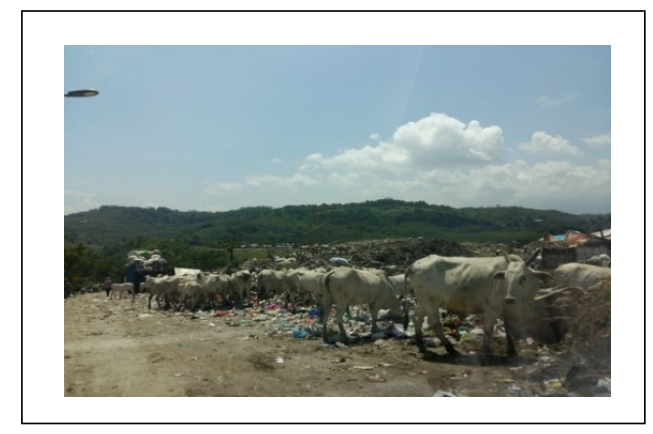

Gambar 5. Kegiatan Penggembalaan Sapi di lokasi TPA Jatibarang Sumber : Observasi, 2018 


\subsubsection{Kantin Gas Metana dengan Pembayaran menggunakan Plastik}

Program kantin gas metana dengan pembayaran menggunakan kantong plastik ini merupakan upaya percontohan bagi warga setempat yang memanfaatkan distribusi gas metana dari TPA Jatibarang sebagai bahan bakar memasak. Kemudian hasil masakan dari kompor gas metana tersebut dijual kepada para pemulung yang aktif di lokasi TPA Jatibarang, yang dibayar dengan mengumpulkan sampah plastik. Sistem ini dapat membantu mengurangi timbunan sampah, terutama sampah anorganik, serta dapat memberikan manfaat yang baik bagi penduduk setempat yang mendapatkan pembayaran berupa sampah plastik untuk dapat digunakan lagi, dan bagi pemulung yang memiliki keterbatasan biaya untuk membeli makanan.

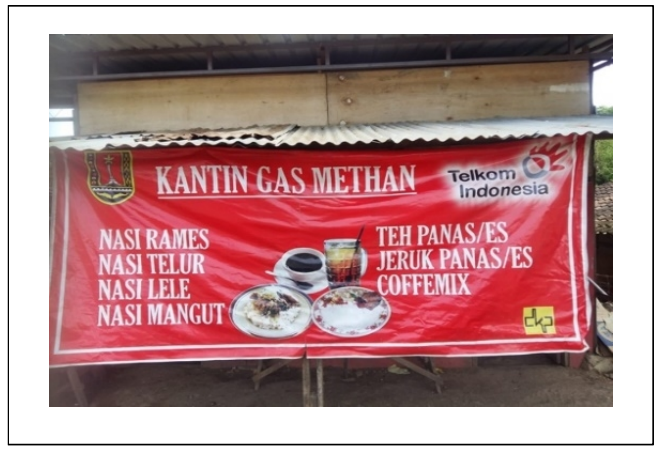

Gambar 6. Kantin Gas Metana di lokasi TPA Jatibarang Sumber: Observasi, 2018

Berdasarkan analisis yang dilakukan, terkait ketersediaan dan pemanfaatan fasilitas yang digunakan, maka pengelolaan sampah TPA Jatibarang secara keseluruhan dapat dikatakan cukup baik. Berikut merupakan tabel analisis pengelolaan sampah TPA Jatibarang.

Tabel 1. Analisis Pengelolaan Sampah TPA Jatibarang

\begin{tabular}{|c|c|c|c|c|c|}
\hline \multirow[t]{3}{*}{ Fasilitas Persampahan } & \multicolumn{4}{|c|}{ Pengelolaan sampah } & \multirow[t]{3}{*}{ Keterangan } \\
\hline & \multicolumn{2}{|c|}{ Ketersediaan } & \multicolumn{2}{|c|}{ Penggunaan } & \\
\hline & Tersedia & $\begin{array}{c}\text { Tidak } \\
\text { Tersedia }\end{array}$ & Digunakan & $\begin{array}{c}\text { Tidak } \\
\text { Digunakan }\end{array}$ & \\
\hline $\begin{array}{l}\text { Saluran drainase untuk } \\
\text { mengontrol air hujan }\end{array}$ & $\sqrt{ }$ & - & $\sqrt{ }$ & - & $\begin{array}{l}\text { Cukup baik, berupa } \\
\text { sungai }\end{array}$ \\
\hline $\begin{array}{l}\text { Saluran untuk } \\
\text { pengumpulan lindi dan } \\
\text { instalasi pengolahan }\end{array}$ & $\sqrt{ }$ & - & - & $\sqrt{ }$ & $\begin{array}{l}\text { Cukup baik, berupa } \\
\text { kolam, dan sudah } \\
\text { tidak digunakan }\end{array}$ \\
\hline Pos kontrol operasional & $\sqrt{ }$ & - & $\sqrt{ }$ & - & $\begin{array}{l}\text { Cukup baik, sudah } \\
\text { tersedia fasilitasnya }\end{array}$ \\
\hline Fasilitas kontrol gas & $\sqrt{ }$ & - & $\sqrt{ }$ & - & Cukup baik, berupa \\
\hline
\end{tabular}


Jurnal Planologi Vol. 17 No. 2, Oktober 2020

Available : http://jurnal.unissula.ac.id/index.php/psa

\begin{tabular}{|c|c|c|c|c|c|}
\hline \multirow[t]{3}{*}{ Fasilitas Persampahan } & \multicolumn{4}{|c|}{ Pengelolaan sampah } & \multirow[t]{3}{*}{ Keterangan } \\
\hline & \multicolumn{2}{|c|}{ Ketersediaan } & \multicolumn{2}{|c|}{ Penggunaan } & \\
\hline & Tersedia & $\begin{array}{c}\text { Tidak } \\
\text { Tersedia }\end{array}$ & Digunakan & $\begin{array}{c}\text { Tidak } \\
\text { Digunakan }\end{array}$ & \\
\hline metana & & & & & $\begin{array}{l}\text { pipa dengan } \\
\text { pengukur tekanan }\end{array}$ \\
\hline Alat berat & $\sqrt{ }$ & - & $\sqrt{ }$ & - & $\begin{array}{l}\text { Cukup baik, sudah } \\
\text { tersedia fasilitasnya }\end{array}$ \\
\hline
\end{tabular}

\section{KESIMPULAN DAN SARAN}

\subsection{Kesimpulan}

Berdasarkan hasil observasi dan analisis, menunjukkan bahwa pengelolaan sampah di TPA Jatibarang sudah cukup baik. Hal ini dapat dilihat dari sudah tersedianya fasilitas persampahan, seperti: saluran drainase yang berupa sungai, instalasi pengumpul dan pengolahan air lindi yang berupa kolam lindi, pos kontrol operasional, pengontrol gas metana yang berupa pipa untuk mengukur tekanan gas metana, dan juga berbagai alat berat yang digunakan dalam proses pengolahan sampah. Selain itu juga sudah tersedianya pengolahan sampah yang bisa langsung dimanfaatkan oleh masyarakat, seperti: pengomposan sampah yang dapat digunakan sebagai pupuk, pemanfaatan gas metana untuk memasak, pengurangan sampah dengan penggembalaan sampah, serta adanya kantin gas metana yang pembayarannya dengan menggunakan sampah plastik.

\subsection{Saran}

Saran dari hasil penelitian ini kepada Pemerintah, meskipun pengelolaan sampah di TPA Jatibarang sudah cukup baik, namun kedepannya diperlukan adanya perencanaan yang lebih komprehensif, baik terkait aspek sarana dan prasarana maupun pengelolaanya. Hal ini disebebkan bahwa semakin bertambahnya penduduk Kota Semarang nantinya, akan dapat meningkatkan volume pembuangan/ sampah. Sehingga diharapkan pengelolaan sampah bisa maksimal dan tidak merusak lingkungan. Sedangkan saran untuk masyarakat, diharapkan dapat menerapkan program pengelolaan sampah berbasis 3R (Reuse, Reduce, Recycle).

\section{UCAPAN TERIMA KASIH}

Terima kasih penulis ucapkan kepada Agustin Fitriani dan Aryo Tomy yang telah mendukung dalam penelitian ini, serta itu kepada pengelola Jurnal Planologi yang telah berkenan membantu dalam proses penerbitan jurnal ini. 
Jurnal Planologi Vol. 17 No. 2, Oktober 2020

Available : http://jurnal.unissula.ac.id/index.php/psa

\section{REFERENSI}

Departemen Pekerjaan Umum. (2013). Persyaratan Teknis Penyediaan Pengoperasian, Penutupan atau Rehabilitasi TPA. Retrieved from http://birohukum.pu.go.id/uploads/DPU/2013/Lamp3-PermenPU03-2013.pdf

Ehrig, H.-J. (1983). Quality and quantity of sanitary landfill leachate. Waste Management \& Research, 1(1), 53-68.

Fadhilah, A., Sugianto, H., Hadi, K., Firmandhani, S. W., Murtini, T. W., \& Pandelaki, E. E. (2011). Kajian Pengelolaan Sampah Kampus Jurusan Arsitektur Fakultas Teknik Universitas Diponegoro. Modul, 11(2).

Haivadakis, C. P., Findikakis, A. N., Papelis, C., \& Leckie, J. O. (1988). The mountain view controlled landfill project field experiment. Waste Management \& Research, 6(1), 103-114.

https://bisnis.tempo.co/read/1101819/pembangkit-listrik-sampah-jatibarang-beroperasioktober-2018/full\&view=okDamanhuri, E and Padmi, T. (2010). PENGELOLAAN $S A M P A H . \quad$ Retrieved from https://s3.amazonaws.com/academia.edu.documents/31175121/diktatsampah-2010bag-13.pdf?AWSAccessKeyId=AKIAIWOWYYGZ2Y53UL3A\&Expires $=1542184049 \& S$ ignature $=\mathrm{Urm} \% 2 \mathrm{FzD} 2 \% 2 \mathrm{BzR} 4 \% 2 \mathrm{BBOq} 5 \mathrm{yKIQozodXkw} \% 3 \mathrm{D} \&$ response-contentdisposition=inline \%3B filename\%3DPengelolaan_Sampah.pdf

https://suaramerdeka.news/berburu-energi-baru-dari-timbunan-sampah/

Indonesia Sanitation Sector Development Program. (2010). Document of Indonesia Sanitation Sector Development Program. Semarang: Badan Lingkungan Hidup Kota Semarang.

Jumlah Penduduk Indonesia Tahun 2018 - TUMOUTOUNEWS. (2018). Retrieved November 14, 2018, from https://tumoutounews.com/2018/05/10/jumlah-pendudukindonesia-tahun-2018/

Produksi sampah plastik Indonesia 5,4 juta ton per tahun - ANTARA News. (2014). Retrieved November 14, 2018, from https://www.antaranews.com/berita/417287/produksi-sampah-plastik-indonesia-54juta-ton-per-tahun.

Republik Indonesia, P. P. (2012). PP no 81 tahun 2012 tentang Pengelolaan Sampah Rumah Tangga dan Sejenis Sampah Rumah Tangga. Republika. Retrieved from http://www.researchgate.net/profile/Agus_Sugiyono/publication/264784175_Analisis _Manfaat_dan_Biaya_Sosial/links/53ef4ede0cf2711e0c42f08f.pdf\%5Cnhttp://ferryfe bub.lecture.ub.ac.id/files/2013/01/Bagian-VI-Analisis-Biaya-dan-

Mnafaat.pdf\%5Cnhttps://www.gov.uk

Republik Indonesia, P. P. (2012). PP no 81 tahun 2012 tentang Pengelolaan Sampah Rumah Tangga dan Sejenis Sampah Rumah Tangga. Republika. Retrieved from http://www.researchgate.net/profile/Agus_Sugiyono/publication/264784175_Analisis Manfaat_dan_Biaya_Sosial/links/53ef4ede0cf2711e0c42f08f.pdf\%5Cnhttp://ferryfe bub.lecture.ub.ac.id/files/2013/01/Bagian-VI-Analisis-Biaya-danMnafaat.pdf\%5Cnhttps://www.gov.uk

Riswan, R., Sunoko, H. R., \& Hadiyarto, A. (2012). Pengelolaan Sampah Rumah Tangga Di Kecamatan Daha Selatan. Jurnal Ilmu Lingkungan, 9(1), 31. https://doi.org/10.14710/jil.9.1.31-38.

Sucipto, Cecep Dani. (2012). Teknologi Pengolahan Daur Ulang Sampah. Yogyakarta: Gosyen Publishing.

Sulistyorini, L. (2005). Pengelolaan sampah dengan cara menjadikannya kompos. Jurnal

Intan Muning Harjanti, Pratamaningtyas Anggraini |196 Pengelolaan Sampah di TPA Jatibarang, Kota Semarang 
Jurnal Planologi Vol. 17 No. 2, Oktober 2020 Available : http://jurnal.unissula.ac.id/index.php/psa

Kesehatan Lingkungan, 2(1), 77-84.

Universitas Gadjah Mada: Penduduk Indonesia Mencapai 305,7 Juta di Tahun 2035. (2017). Retrieved November 15, 2018, from https://ugm.ac.id/id/berita/14575penduduk.indonesia.mencapai.3057.juta.di.tahun.2035.

U. N. 18 T. (2008). Undang-Undang Republik Indonesia Nomor 18 Tahun 2008Tentang Pengelolaan Sampah. In Republik Indonesia (pp. 1-46). https://doi.org/DOI 10.1016/j.trac.2006.12.007. 